\title{
ASSESSING FUNCTIONAL ROLE AND COMMUNITY DYNAMICS OF WHITEBARK PINE AT ALPINE TREELINE, Grand Teton National PARK
}

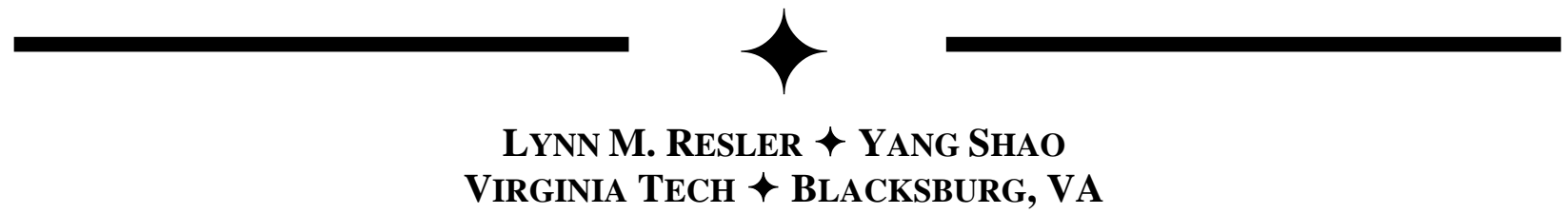

\section{$\uparrow \quad$ ABSTRACT}

Whitebark pine (Pinus albicaulis) is a keystone and foundation tree species in high elevation ecosystems of the Rocky Mountains. At alpine treelines along the eastern Rocky Mountain Front and in the Greater Yellowstone Ecosystem, whitebark pine often initiates tree islands through facilitation, thereby shaping vegetation pattern. This role will likely diminish if whitebark pine succumbs to white pine blister rust infection, climate change stress, and mountain pine beetle infestations. Here, we established baseline measurements of whitebark pine's importance and blister infection rates at two alpine treelines in Grand Teton National Park. Our specific objectives were to: 1) examine the potential relationship between whitebark pine establishment and krummholz tree island formation at the upper alpine treeline ecotone in GTNP; 2) characterize blister rust infection rate and intensity at two treeline study areas and in whitebark pine growing both solitarily and within tree islands; and 3) characterize the biophysical environments a) where whitebark pine is/is not a majority tree island initiator, and b) with varying blister rust infection rates in treeline whitebark pine. In July 2015, we field-sampled treeline composition and blister rust infection in all krummholz whitebark pine in a total of 40 study plots. Preliminary results reveal: 1) that whitebark pine is a substantial component of treeline ecosystems, but is not a significant majority tree island initiator, and 2) blister rust infection levels for both study areas combined is $15.65 \%$. Blister rust and mountain pine beetle interactions were not evident at the two study areas. This work provides important baseline measurements for understanding how community structure and composition may be altered given infestation by pathogens and pests in GTNP, especially in light of changing climate regimes.

\section{$\uparrow \quad$ INTRODUCTION}

Whitebark pine (Pinus albicaulis) is a keystone species of upper subalpine and treeline forests throughout its range in the western mountains of the United States and Canada (Tomback et al. 2001, Ellison et al. 2005, Tomback and Achuff 2010). In subalpine forests, whitebark pine trees foster forest biodiversity in numerous ways, including provision of an important wildlife food source, and by fostering community development (e.g., Tomback et al. 2001). Along the eastern Rocky Mountain Front in the Northern Rocky Mountains and in the Greater Yellowstone Ecosystem (GYE), whitebark pine sometimes initiates tree islands through facilitation, thereby shaping vegetation patterns (Haebeck 1969, Resler and Tomback 2008, Smith-McKenna et al. 2011). These roles will likely diminish if whitebark pine succumbs to disturbance factors such as blister rust infection, climate change stress (Tomback and Resler 2007) and mountain pine beetle infestations (e.g., Bockino and Tinker 2012).

At many North American alpine treeline ecotones (ATEs) throughout the range of whitebark pine, vegetation pattern is characterized by the presence of tree islands, or clusters of trees surrounded by herbaceous vegetation. Change in vegetation patterns at the ATE is often expected to manifest itself as an upward migration of vegetation belts that include conifer invasion and eventual exclusion of alpine tundra (e.g., Hall and Fagre 2003 for Glacier National Park, Schrag et al. 2008 for the GYE). Landscape responses of treelines, however, have been varied worldwide with measureable advance reported in approximately half (Harsch et al. 2009). Treelines of the Rocky Mountains of North America have, in particular, exhibited variable responses with some research reporting conifer infilling and densification 
(Butler et al. 1994, Klasner and Fagre 2002), but no measureable advance at the study resolutions. Given the pine's role in community development at alpine treeline, and disturbance factors that threaten this role, Rocky Mountain ATEs where whitebark pine is present are ideal locations to study interacting factors affecting treeline dynamics.

In Grand Teton National Park (GTNP), studies assessing alpine treelines are few. One exception is Schrag et al. (2008) who simulated hypothetical future climate scenarios and monitored the response of whitebark pine and its conifer associates. Results indicated that conifer distributions may be altered by increased temperature and dominant pine forests may be replaced by fir and spruce forests. Surveys have been made of whitebark pine health and infection rates in subalpine stands (e.g., Bockino et al. 2013); however the importance of whitebark pine specifically for treeline ecosystem dynamics within GTNP has not been assessed.

A study that establishes important baseline measurements for alpine treelines is warranted for this key protected region, especially in light of interactions between disturbance, climate and vegetation dynamics. Thus, in order to fill this gap, we assessed alpine treelines where whitebark pine is present in GTNP. Our specific objectives were: 1) to obtain exploratory field observations to examine the potential relationship between whitebark pine establishment and krummholz tree island formation at the upper ATE in GTNP; 2) to characterize blister rust infection rate and intensity at two treeline study areas and in whitebark pine growing both solitarily and within tree islands at the upper ATE; and 3) to characterize the biophysical environments a) where whitebark pine is/is not a majority tree island initiator, and b) with varying blister rust infection rates in treeline whitebark pine.

\section{Whitebark pine and tree island development}

Whitebark pine is restricted to high elevations with a few conifer associates, including (but not limited to) subalpine fir (Abies lasiocarpa), Engelmann spruce (Picea engelmannii), and lodgepole pine (Pinus contorta). The pine has a spatially heterogeneous distribution in mountainous topography, which subjects it to a wide range of environmental conditions that impact its local distributions, densities and associates (Tomback and Achuff 2010).

At some ATEs in North America, an important functional role of whitebark pine is tree island initiation - a role that likely results both from the sheltered seed caching sites selected by Clark's nutcrackers (Nucifraga columbiana, Family Corvidae) and the hardiness of the seedlings (McCaughey and Tomback 2001). Whereas the seeds of whitebark pine's forest associates are mostly wind-dispersed (McCaughey and Tomback 2001), whitebark pine seedlings grow primarily from seeds that are stored, but not retrieved by the Clark's nutcracker (Hutchins and Lanner 1982, Tomback 1982). Nutcrackers typically harvest whitebark pine seeds from the subalpine forest and transport them to treeline for seed caching (Tomback 1986, Baud 1993) near "landmarks," which are often sheltered sites in the lee of trees, rocks, logs, and stumps (Tomback 1978; Figure 1). These sheltered sites contribute to whitebark pine survival because of enhanced snow burial, protection from blowing ice, reduced sky exposure, and greater soil moisture after snowmelt (Germino et al. 2002, Smith et al. 2003, Resler et al. 2005). Germination of other conifers follows snowmelt in microsites leeward of tree islands and in the lee of microtopography (Resler et al. 2005). The presence of whitebark pine may further mitigate shelter sites, for example, by reducing sky exposure or moderating temperature and soil moisture.

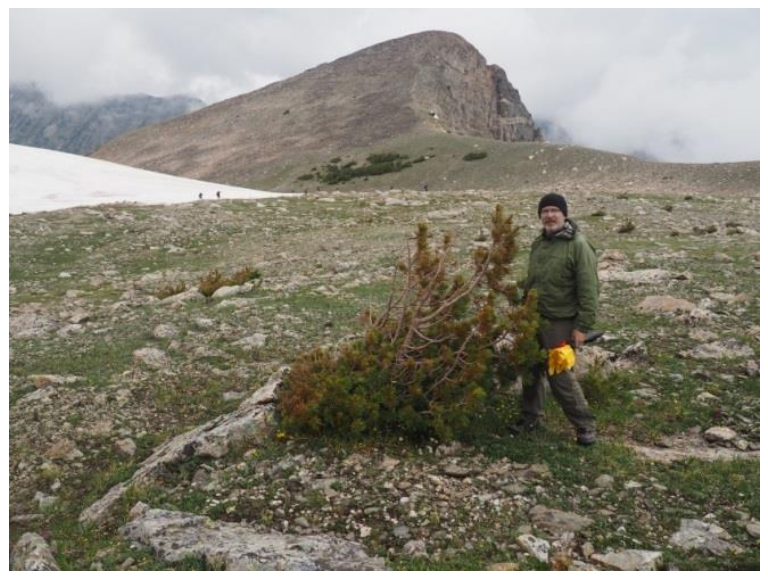

Figure 1. Whitebark pine growing in lee of boulder, ATE, Paintbrush Divide, Grand Teton National Park.

Furthermore, newly geminated whitebark pine seedlings are relatively robust (Arno and Hoff 1990, McCaughey and Tomback 2001); established trees also show greater general vigor than other treeline conifers (Blakeslee 2012). Combined, these factors enable pioneer colonization under harsh conditions, and pave the way for less hardy species to establish in their lee, promoting tree island development (Resler and Tomback 2008).

Despite the relative consistency in conifer associations across treelines across its range, 
whitebark pine's role in tree island development varies geographically. Previous studies by Resler and Tomback (2008), Resler and Fonstad (2009), and Smith et al. (2011) showed that whitebark pine initiates tree islands more than any other conifer area along the eastern Rocky Mountain Front of Montana. Callaway (1998) also found that whitebark pine served as an important nurse tree for subalpine fir on exposed sites in the upper subalpine in the northern U.S. Rocky Mountains. However, where climate conditions are more moderate, subalpine fir was found to be more important than whitebark pine in community development (Resler et al. 2005) - a pattern also noted by Tomback et al. (2014) in moist, Canadian sites. Under the assumption that the relative importance of facilitation at a location relates to species-specific tolerances to abiotic stress (Bertness and Callaway 1994), Resler et al. (2014) characterized the relationship between the role of whitebark pine in tree island facilitation and several biophysical variables. They found that temperature was the most important predictor of whitebark pine as a majority tree island initiator, with colder temperatures correlating to higher initiation by the pine as opposed to other treeline conifers.

\section{Coupled effects of climate change and blister rust at alpine treeline}

At a global scale, treeline position is primarily controlled by temperature. However, at local scales, treeline is controlled by multiple mechanisms, such as propagule/seed availability, microclimate, microtopography, and community structure; combined, these factors confound its relationship with temperature (Malanson et al. 2007). Furthermore, geographic location and latitude influences treeline pattern (Young and León 2007), and ultimately, response to changing climate.

Until recently, predictions of vegetation shifts at ATEs have not factored in species-specific responses to environmental change, much less the influence of pathogens. The latter is likely because few pathogens have consequences on as large an ecological scale as does blister rust, caused by the introduced fungal pathogen Cronartium ribicola.

Tomback and Resler (2007) presented a conceptual model of the potential outcomes of interactions among invasive pathogens, climate change, and whitebark pine whereby they proposed blister rust threatens the existence of whitebark pine in the ATE in two primary ways (Figure 2). First, as trees in the subalpine forest zone succumb to blister rust, they lose their ability to produce seeds (e.g., Hoff et al.
2001, McKinney and Tomback 2007), so fewer seeds are available for nutcrackers to disperse to the alpine treeline ecotone (Tomback 1986). Second, blister rust is killing established trees in the ecotone (Resler and Tomback 2008) before they facilitate the recruitment of other conifers. With the diminished presence of whitebark pine, the dynamics of treeline establishment could be disrupted, and treelines would result in altered community structure. With fewer whitebark pine at treeline, tree island formation may be delayed or precluded (Tomback and Resler 2007). This process has recently been simulated using agent-based modeling (Smith-McKenna et al. 2014). Loss of whitebark pine may limit the response of treeline to warming temperatures, leading to the perception that treeline is not moving up or moving more slowly than suitable temperature zones would suggest (Tomback and Resler 2007). Potential implications include a loss of treeline biodiversity as species composition changes or very sparse to no treeline community development under the harshest conditions. The GYE is near the southernmost limit of whitebark pine's distribution. Romme and Turner (1991) examined the effects of three general climate change scenarios on whitebark pine and other forest species in the GYE and found that for all scenarios, whitebark pine moves higher in elevation and thus occupies less area. The damage and mortality in whitebark pine from blister rust may counter tendencies towards northward or upwards movements if tree island initiation is reduced in frequency. Thus, the effects of blister rust may be at landscape scale, impacting vegetation development and even countering global warming predictions.

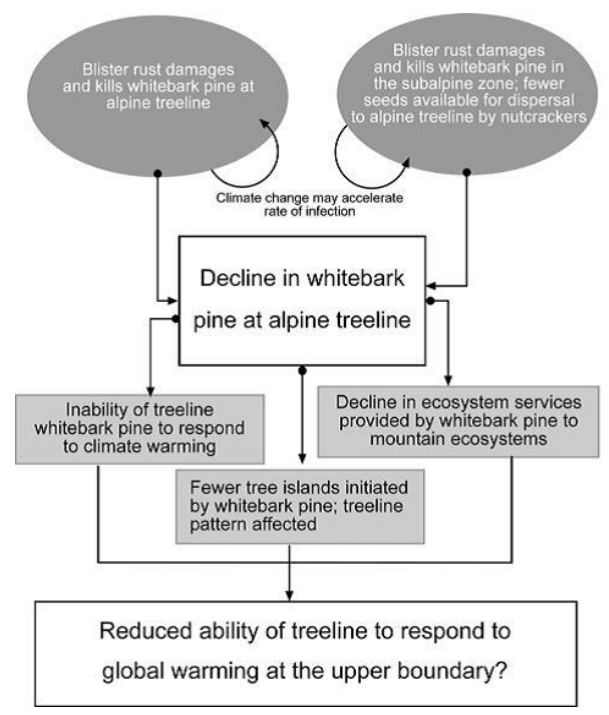

Figure 2. Conceptual model showing interactions among blister rust/climate change and functional role of whitebark pine at alpine treeline. (Source: Tomback and Resler 2007). 


\section{STUDY AREA AND METHODS}

Based on consultation with GTNP Park staff, two general treeline study areas were selected: Paintbrush Divide/Holly Lake and Hurricane Pass/ Avalanche Basin. Study area characteristics are shown in Table 1. The Hurricane Pass/Avalanche Basin site is proximal to the Schoolroom Glacier (Figure 3; area $\left.\sim 0.0081 \mathrm{~km}^{2}\right)$, which lies at approximately $3200 \mathrm{~m}$ $(10,400 \mathrm{ft})$, and is currently receding. Through modeling, our previous work (e.g., Smith et al. 2011, Smith-McKenna et al. 2014) revealed that proximity to glaciers and streams may impact blister rust infection rates, since they are a likely moisture and humidity source.

Table 1. Characteristics of Study Areas

\begin{tabular}{|c|c|c|}
\hline & $\begin{array}{l}\text { Holly } \\
\text { Lake/Paintbrush } \\
\text { Divide }\end{array}$ & $\begin{array}{l}\text { Avalanche } \\
\text { Basin/Hurricane } \\
\text { Pass }\end{array}$ \\
\hline Plot Size, No. & $227 \mathrm{~m}^{2}, \mathrm{~N}=20$ & $227 \mathrm{~m}^{2}, \mathrm{~N}=20$ \\
\hline $\begin{array}{l}\text { Elevation } \\
\text { Range }\end{array}$ & $3051-3261 \mathrm{~m}$ & 3038-3204 m \\
\hline Lat/Long & $\begin{array}{l}43^{\circ} 47^{\prime} 34^{\prime \prime} \mathrm{N}, \\
110^{\circ} 47^{\prime} 54^{\prime \prime} \mathrm{W}\end{array}$ & $\begin{array}{c}43^{\circ} 43^{\prime} 41^{\prime \prime} \mathrm{N}, \\
110^{\circ} 51^{\prime} 02^{\prime \prime} \mathrm{W}\end{array}$ \\
\hline Aspect & NE, SE, SW, NW & $\mathrm{NE}, \mathrm{SE}, \mathrm{NW}$ \\
\hline $\begin{array}{l}\text { Tree } \\
\text { Composition }\end{array}$ & $\begin{array}{l}\text { Pinus albicaulis } \\
\text { Abies lasiocarpa } \\
\text { Picea Engelmannii }\end{array}$ & $\begin{array}{l}\text { Pinus albicaulis } \\
\text { Abies lasiocarpa } \\
\text { Picea Engelmannii } \\
\text { Pseudotsuga } \\
\text { menziesii }\end{array}$ \\
\hline
\end{tabular}

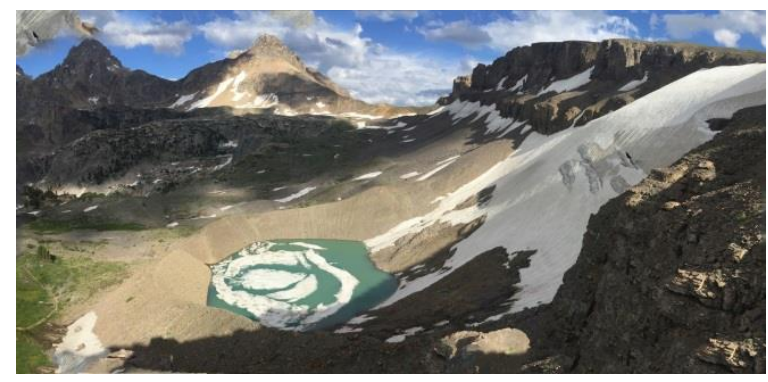

Figure 3. Schoolroom Glacier, GTNP. Photo by Brian Bond, taken from Hurricane Pass looking toward Avalanche Basin.

Thirty year climate normals for MaySeptember 1981-2010 (PRISM) revealed that growing season temperatures are generally higher and precipitation is generally lower at the Paintbrush Divide/Holly Lake site (Figure 4).

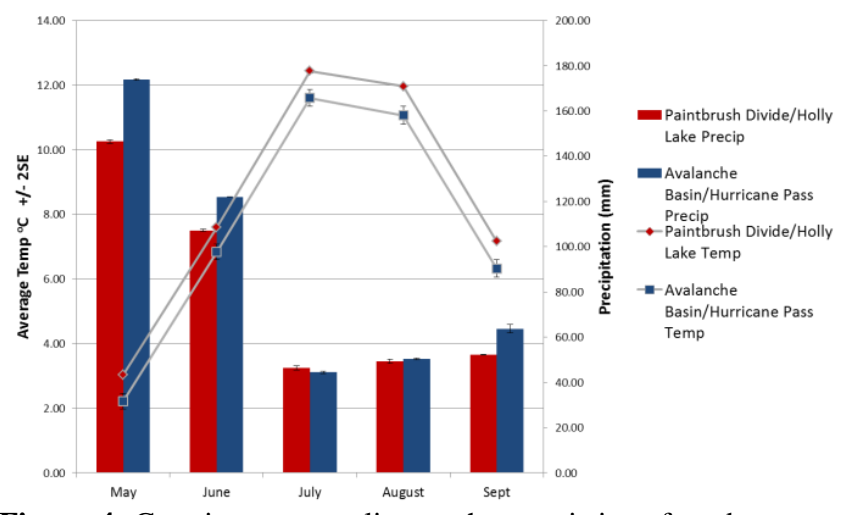

Figure 4. Growing season climate characteristics of study sites (PRISM, 30 year climate normals, 1981-2010).

\section{Field methods}

In July 2015, we field-sampled treeline composition and blister rust infection rates of all krummholz whitebark pine in a total of 40 study plots at the two study areas. Fieldwork in support of Objectives 1-3 focused on the upper elevations of the alpine treeline ecotone, where trees are environmentally stunted, flagged and frequently grow as krummholz. Vegetation sampling inside GTNP was conducted under a NPS permit.

We sampled the composition of upper ATE communities using 20 circular $(\mathrm{r}=8.5 \mathrm{~m}$, area $\sim 227$ $\mathrm{m}^{2}$ ) sampling plots at each of the two study areas. Prior to entering the field we used ArcGIS and aerial photographs to stratify sampling areas by slope aspect; within each strata, we randomly selected 50 points positioned at least $50 \mathrm{~m}$ apart (to reduce potential spatial autocorrelation) at each site to serve as potential study plot centroids. Coordinates of each random point were uploaded into a Trimble GeoXT handheld GPS with submeter accuracy. In the field, we navigated to a total of 20 points per study area, and designated the coordinates as the plot centroid. Plot size was determined based on our previous sampling strategies of whitebark pine ATE communities (e.g., Smith-McKenna et al. 2013). Since tree-pathogen interactions are likely to differ strongly with mesoclimate as influenced by slope, aspect, and elevation, our goal was to sample over a large range of whitebark pine at the ecotone.

We recorded elevation and aspect of each plot. Within each plot we identified the number and composition of all tree islands and solitary trees, (regardless of age or size) that fell completely or partially within the sampling plot. We measured the longest and shortest dimension of each conifer patch to provide a rough estimate of tree island size. To determine the importance of whitebark pine in tree 
island composition and development, we recorded the number of whitebark pine trees per tree island and noted the starting and leeward conifer(s), and characterized shelter type (if applicable) (i.e., rock, topographic depression, vegetation, or other) following Resler et al. (2005). Finally, for the purpose of describing growth form, we categorized each whitebark pine as krummholz (low growing, often matted, wind-sculpted trees), flagged (trees with asymmetrical foliage indicating wind-damage and ice abrasion) or upright (fully erect). Number of dead trees per plot were also recorded.

To determine blister rust infection in whitebark pine, identification of blister rust infection followed methods by Hoff (1992). To estimate infection rates, we recorded the number of inactive cankers (old cankers that sporulated, with swollen and cracked bark on dead branch or stem), and active cankers (fresh or old aecial sacs; Figure 5) found on each whitebark pine. Since Mountain Pine Beetle (MPB; Dendroctonus ponderosae) is also present in GTNP, and important interactions occur with MPB and white pine blister rust (Bockino and Tinker 2012), we scanned each whitebark pine tree for evidence of MPB, such as the presence of pitch tubes, $\mathrm{j}$-shaped galleries, entrance and emergence holes, and the presence of beetles (e.g., Bockino et al. 2013).

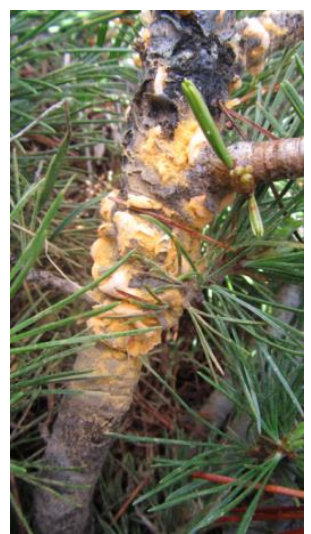

Figure 5. Sporulating (active) white pine blister rust canker on whitebark pine.

\section{Statistical analysis}

Data was tested for normality; nonparametric tests were chosen when the assumptions for normality were not met. To determine if a conifer species is found significantly more as an initial tree island colonizer than other species (Objective 1), we used a $\mathrm{G}$ goodness-of-fit test (McDonald 2009). Tree island composition was summarized with descriptive statistics. Blister rust infection rates (Objective 2) were summarized at the plot and study area level. To compare the incidence of blister rust among sites and between solitary trees and tree islands, we used the nonparametric Mann Whitney $U$ test (McDonald 2009).

To explore relationships between the biophysical environments of the study areas blister rust infection rates in treeline whitebark pine (Objective 3), we derived a suite of biophysical variables that have been shown to correlate with blister rust infection at alpine treeline (Smith et al. 2011, Smith-McKenna et al. 2013). These biophysical variables included: solar radiation, elevation, surface curvature, flow accumulation, aspect, slope angle, precipitation, and temperature. Surface curvature, solar radiation, slope, flow accumulation and aspect were derived from 1/3 arc-second (approximately 10 $\mathrm{m}$ ) digital elevation models, available from the United States Geological Survey. Climate data (30 year normals) were obtained from Precipitation-Elevation Regressions on Independent Slopes Models (i.e., PRISM data). Determining the relationships between the selected biophysical variables is an ongoing analysis; we anticipate its completion by July 2016. However, we have performed preliminary analyses using Spearman's rank correlations.

\section{$\downarrow \quad$ Preliminary ReSUlts}

\section{Functional role of whitebark pine at alpine treeline}

The first objective of our study was to examine the potential relationship between whitebark pine establishment and krummholz tree island formation at the upper ATE in GTNP. In addition to tree island components, whitebark pine trees growing solitarily (i.e., not as a part of tree islands) are of interest here because they are considered: 1) to represent potential for tree island development, and 2) because research has shown the blister rust infection rates are often lower in solitary treeline whitebark pine (e.g., Resler and Tomback 2008).

At Hurricane Pass/Avalanche Basin, there were 136 total whitebark pine, 73 of which were in tree islands, and 63 of which were growing solitarily. There were a total of 138 solitary trees of all represented species (Figure 6), among all the plots (min, median and max number of solitary trees per plot = 0/ha, 242.31/ha and 793.02/ha, respectively). Min, median and max number of tree islands/plot was $0 /$ ha, $66.09 /$ ha and $352.45 /$ ha $(n=45)$. 


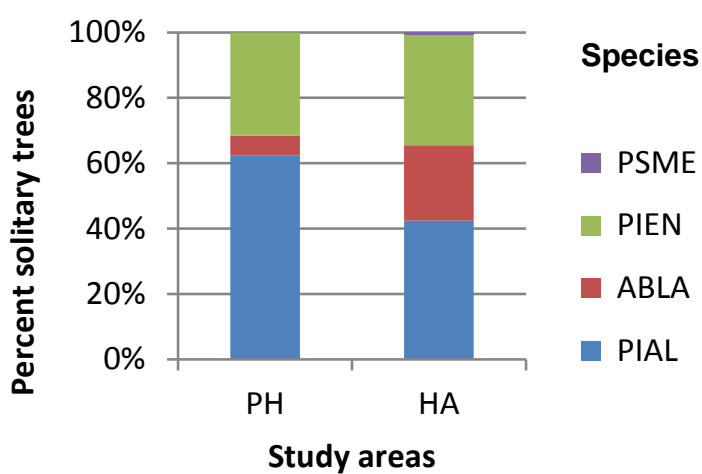

Figure 6. Percent composition of the solitary conifer tree community for each study area. Study areas are abbreviated as follows: $\mathrm{PH}=$ Paintbrush Divide/Holly Lake, HA = Hurricane Pass/Avalanche Basin. Species are abbreviated as follows: PSME = Pseudotsuga menziesii, PIEN = Picea engelmannii, $\mathrm{ABLA}=$ Abies lasiocarpa, $\mathrm{PIAL}=$ Pinus albicaulis.

At Paintbrush Divide/Holly Lake, there were 283 total whitebark pine; 107 were in tree islands, and 176 were growing solitarily. There were a total of 282 solitary trees of all represented species (Figure 6), among all the plots (min, median and max number of solitary trees per plot $=0 / \mathrm{ha}, 550.71 / \mathrm{ha}$ and 1497.92/ha, respectively). Min, median and max number of tree islands/plot was $0 /$ ha, 88.11/ha and $308.40 /$ ha $(n=45)$. Species representation within tree islands by study area is shown in Figure 7.

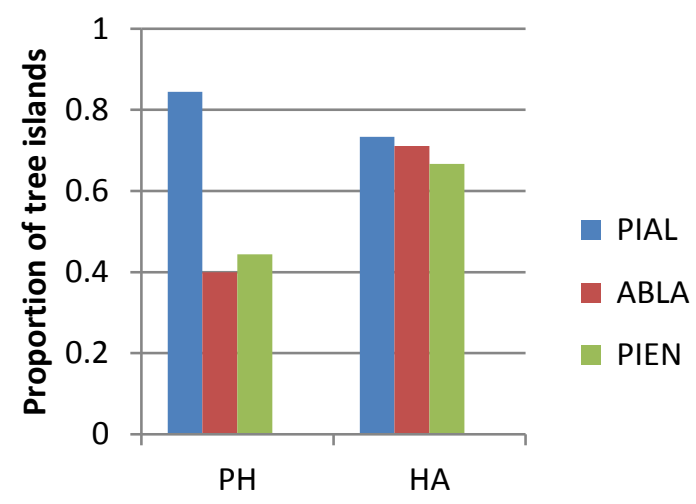

Study areas

Figure 7. The proportion of tree islands within a study area with one or more individuals of each species. Study areas are abbreviated as follows: $\mathrm{PH}=$ Paintbrush Divide/Holly Lake, $\mathrm{HA}=$ Hurricane Pass/Avalanche Basin.

We used $G$ goodness of fit tests to assess whether whitebark pine initiated tree islands significantly more than other common treeline species (subalpine fir and Engelmann spruce). At Hurricane Pass/Avalanche Basin, the G-test revealed that there were no significant differences between observed and expected proportions $(P=0.72)$ among species that initiated tree islands. However, at Paintbrush Divide/ Holly Lake, Engelmann spruce $(n=30)$ initiated tree islands significantly more than both whitebark pine ( $n$ $=7)$ and subalpine fir $(n=8, G=20.86, P<0.001)$. Tree initiation by species is shown in Figure 8.

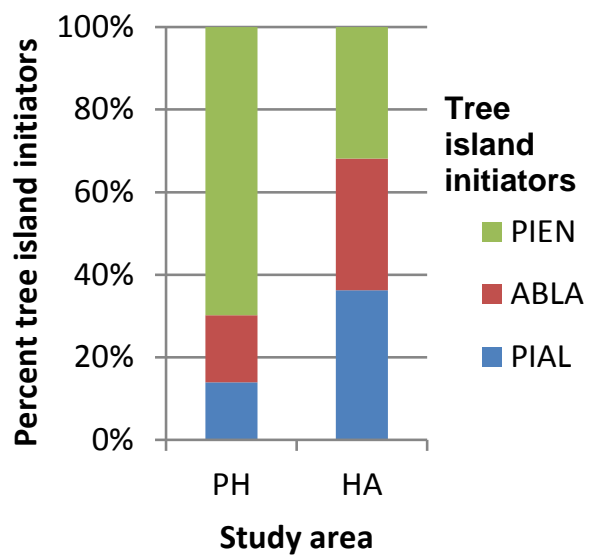

Figure 8. Relative proportional abundance of whitebark pine as a tree island initiator within each study area. Study areas are abbreviated as follows: $\mathrm{PH}=$ Paintbrush Divide/Holly Lake, HA = Hurricane Pass/Avalanche Basin. Species abbreviations listed in Figure 6.

\section{Blister rust infection}

Blister rust was present in krummholz whitebark pine at both study areas. Of all whitebark pine trees measured, $14.7 \%(n=20)$ were infected with blister rust (as evidenced by the presence of at least one active or inactive canker) at Hurricane Pass/ Avalanche Basin. At Paintbrush Divide/Holly Lake $16.6 \%$ were infected $(n=47)$. Although we looked for evidence of MPB in our study plots, we only found two $(n=2)$ krummholz trees with entrance/emergence holes, and these trees were uninfected by blister rust.

At Paintbrush Divide/Holly Lake, we counted seven total dead whitebark pine; one of these trees had obvious signs of blister rust infection. Five $(n=5)$ dead whitebark pine trees were measured at Hurricane Pass/Avalanche Basin, two of which had obvious signs of blister rust infection.

A Mann-Whitney $U$ test was conducted to determine if there was a difference in total cankers between the study areas. The test revealed no significant differences $(Z=-0.26, \quad P=0.79)$ in total cankers (active and inactive) between Paintbrush Divide/Holly Lake $(n=195 ; \overline{\mathrm{x}}=0.69$; $\min =0$; $\max$ $=13)$ and Hurricane Pass/Avalanche Basin $(n=84 ; \overline{\mathrm{x}}$ $=0.65 ; \min =0 ; \max =15)$. 
The spatial distribution of blister rust infection (rate and intensity) was mapped for each of the 20 study plots at Hurricane Pass/Avalanche Basin (Figure 9) and Paintbrush Divide/Holly Lake (Figure $10)$.
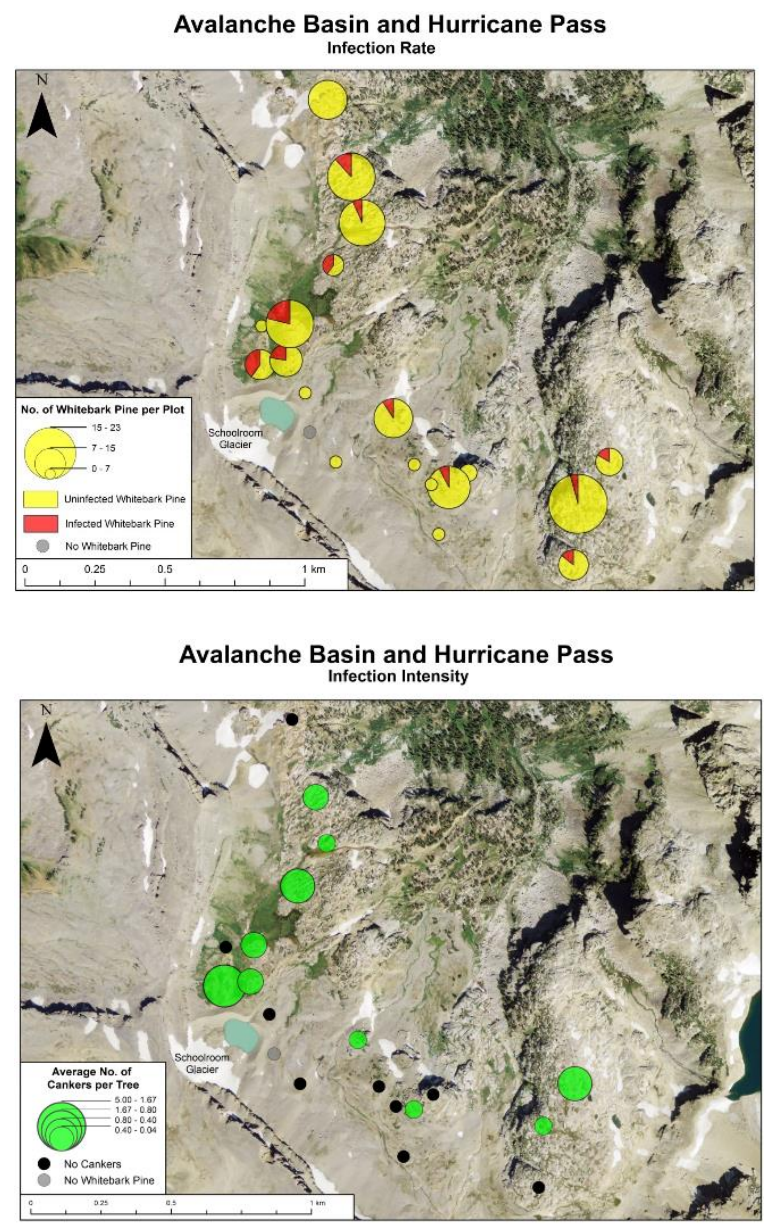

Figure 9. Percent of whitebark pine infected as compared to total whitebark pine per plot (top). Infection intensity mapped as average number of cankers per tree (bottom).

Cool late summer temperatures and high humidity levels are conditions conducive to the spread of blister rust infection (McDonald and Hoff 2001). Through modeling, our previous work (Smith et al. 2011, Smith-McKenna et al. 2014) revealed that proximity to glaciers and streams may impact blister rust infection rates, since they are a likely moisture and humidity source. Although our results are preliminary and warrant further study, proximity to the Schoolroom Glacier, along with higher growing season precipitation rates at Hurricane Pass/Avalanche Basin (Figure 4) do not seem to contribute to higher infection rates or intensities, when compared to Paintbrush Divide/Holly Lake - a site characterized by lower precipitation and substantial distance from the glacier or similar potential moisture source.
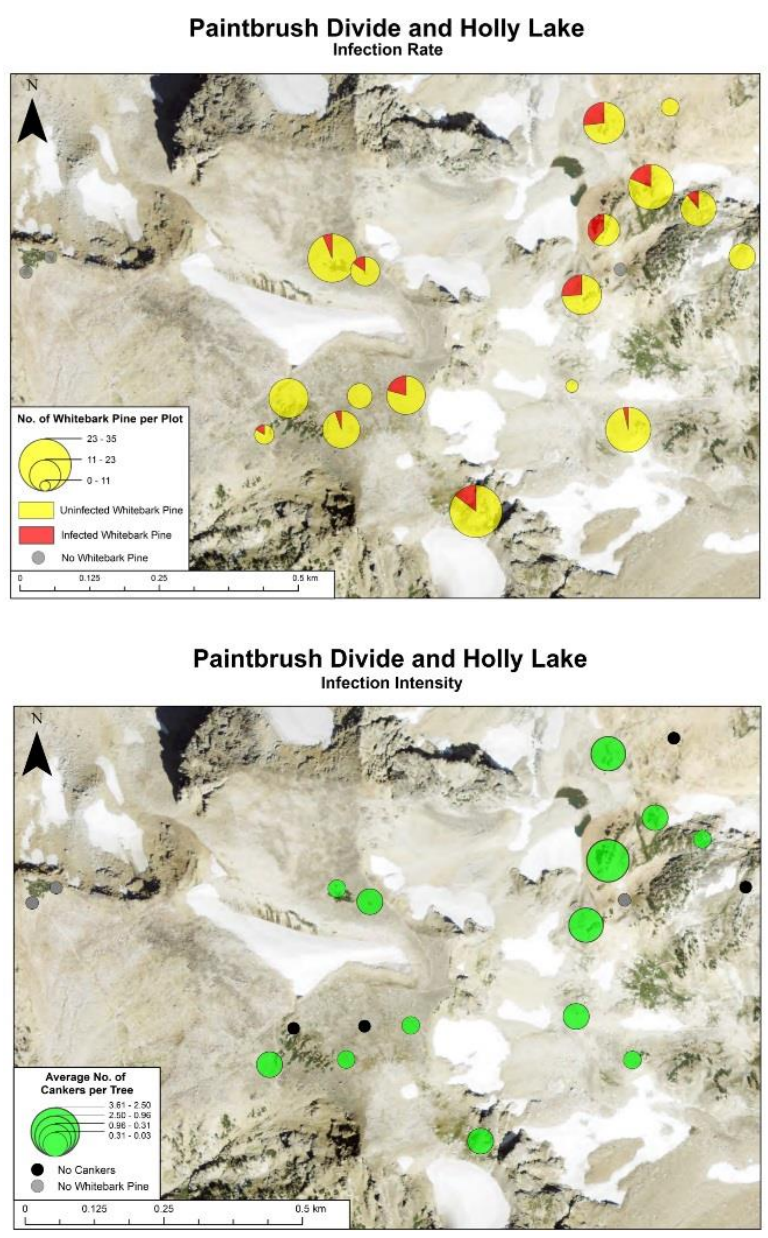

Figure 10. Percent of whitebark pine infected as compared to total whitebark pine per plot (top). Infection intensity mapped as average number of cankers per tree (bottom).

Finally, we assessed whether growth form (trees growing as solitary trees or within tree islands) affected blister rust infection levels. At Hurricane Pass/Avalanche Basin, there were 19 active and inactive cankers in solitary whitebark pine trees, and 65 in tree island whitebark pine. No significant differences $(P>0.05)$ were found between number of cankers/tree in solitary and tree island whitebark pine (Figure 11).

At Paintbrush Divide/Holly Lake, there were 24 active and inactive cankers in solitary whitebark pine trees, and 171 found in tree island whitebark pine. There were significantly more cankers/tree in tree islands than in whitebark pine growing solitarily $(Z=$ 6.13, $P<0.001$, Mann Whitney $U$ test; Figure 11). 


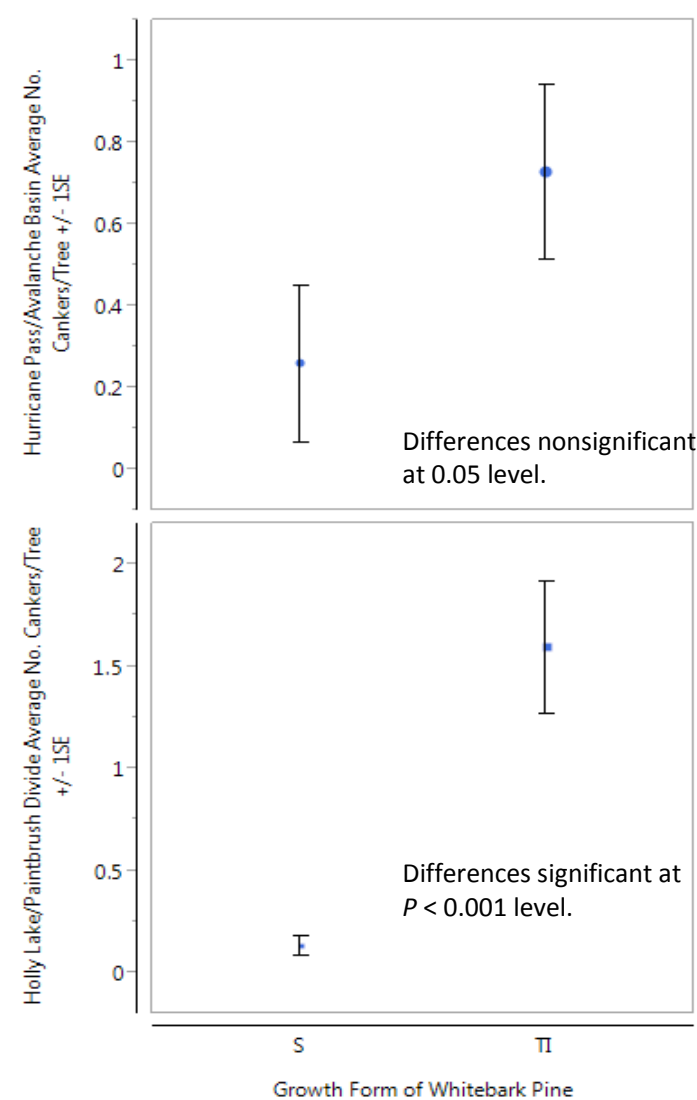

Figure 11. Blister rust infection intensity (no. cankers/whitebark pine) in the GTNP, in tree islands (TI) and in solitary trees $(\mathrm{S})$.

Previous studies have highlighted the importance of microsite pattern in blister rust infection rates. For example, in Resler and Tomback (2008), Smith (2011) and Smith-McKenna (2013), we have found significantly more cankers per tree in tree islands than in solitary trees, suggesting that vegetation pattern and its generation of distinct microclimate (i.e., Pyatt 2013) may be a primary influence on blister rust infection rates in treeline whitebark pine.

\section{Biophysical characteristics}

The third objective of this study was to characterize the biophysical environments a) where whitebark pine is/is not a majority tree island initiator, and $b$ ) with varying blister rust infection rates in treeline whitebark pine. As discussed in above in 'Methods', derivation of GIS variables for the biophysical analyses has been completed, but statistical analysis of the relationship between these biophysical variables and blister rust infection is in progress. Anticipated completion is March 2016. Preliminary statistical analyses revealed a significant correlation between positive surface curvature (convexity) and no.cankers/tree Spearman's $\rho=0.41$, $P<0.01)$.

\section{$\uparrow \quad$ IMPLICATIONS AND OUTCOMES}

We have yet to understand the full consequences of ecological interactions altered by pathogens and pests in Rocky Mountain alpine treelines; this is especially true in communities where keystone species, such as whitebark pine, are present. This work contributes to our baseline knowledge on treeline communities and their dynamics in GTNP. Primary outcomes of this work include: 1) a unique, georeferenced field dataset of treeline communities in Grand Teton National Park that will provide important baseline information; 2) an estimate of blister rust infection rates and mortality in ATE whitebark pine communities; and 3) an assessment of biophysical characteristics associated with tree island development and blister rust, specifically at alpine treeline. The latter will help address the importance of whitebark pine in the continued development of tree islands under current climate scenarios and how this role may vary geographically. Preliminary results of this work related to blister rust incidence and glacier proximity were presented at a regional geography conference in November 2015 (SEDAAG 2015).

Furthermore, a manuscript has been submitted that contextualizes some of the results of this work within the larger framework of our knowledge on whitebark pine ATEs throughout the pine's range in the Rocky Mountains, and an additional manuscript is in preparation. With information obtained in this study we can further refine models to help Park staff assess how an introduced pathogen, by reducing the ability of its host tree to facilitate the establishment of other tree species, will affect tree species ranges and the landscape-level ecotone response to climate change in GTNP and beyond.

\section{$\uparrow \quad$ ACKNOWLEDGEMENTS}

This work was financially supported by a grant from the UW-NPS Research Station. Kelly McCloskey and Kathy Mellander provided helpful feedback on the project goals and design. Thanks to Celeste Havener for her cheerful and helpful logistical correspondence and to Dr. Harold Bergman at the UW-NPS Research Station. Special thanks to the knowledgeable staff at Jenny Lake Ranger Station for their kind support and time in permit issuance; exceedingly high accolades go to "Goldie" Morris who went above and beyond. 


\section{$\uparrow \quad$ Literature CITED}

Arno, S.F., and R.J. Hoff. 1990. Whitebark pine (Pinus albicaulis Engelm). In: R.M. Burns, and B.H. Honkala (Technical Coordinators), Silvics of North America, Vol. 1, Conifers., USDA Forest Service, Washington, D.C. Agriculture Handbook 654:268-279.

Baud, K.S. 1993. Simulating Clark's Nutcracker caching behavior: Germination and predation of seed caches. [Thesis] University of Colorado at Denver, Denver, CO.

Bertness, M.D., and R. Callaway. 1994. Positive interactions in communities. Trends in Ecology and Evolution 9:191-193.

Blakeslee, S.C. 2012. Assessing whitebark pine vigor and facilitation roles in the alpine treeline ecotone. [Thesis] University of Colorado at Denver, Denver, CO.

Bockino, N.K., and D.B. Tinker. 2012. Interactions of white pine blister rust and mountain pine beetle in whitebark pine ecosystems in the southern Greater Yellowstone Area. Natural Areas Journal 32:31-40.

Bockino, N.K., E. Janssen, and K. McCloskey. 2013. A 2013 update: Whitebark pine monitoring in Grand Teton National Park 2007-2013. Technical Report, Grand Teton National Park Division of Science and Resource Management, Moose, WY.

Butler, D.R., G.P. Malanson, and D.M. Cairns. 1994. Stability of alpine treeline in Glacier National Park, Montana, U.S.A. Phytocoenologia 22:485-500.

Callaway, R.M. 1998. Competition and facilitation on elevation gradients in subalpine forests of the northern Rocky Mountains, USA. Oikos 82:561-573.

Ellison, A.M., M.S. Bank, B.D. Clinton, E.A. Colburn, K. Elliott, C.R. Ford, D.R. Foster, B.D. Kloeppel, J.D. Knoepp, G.M. Lovett, J. Mohan, D.A. Orwig, N.L. Rodenhouse, W.V. Sobczak, K.A. Stinson, J.K. Stone, C.M. Swan, J. Thompson, B. Von Holle, and J.R. Webster. 2005. Loss of foundation species: Consequences for the structure and dynamics of forested ecosystems. Frontiers in Ecology and the Environment 3:479-486.

Germino, M.J., W.K. Smith, and C. Resor. 2002. Conifer seedling distribution and survival in an alpine-treeline ecotone. Plant Ecology 162:157-168.

Habeck, J. 1969. A gradient analysis of a timberline zone at Logan Pass, Glacier Park, Montana. Northwest Science 43:65-75.
Hall, M., and D.B. Fagre. 2003. Modeled climateinduced glacier change in Glacier National Park, 1850-2100. BioScience 53:131-140.

Harsch, M.A., P.E. Hulme, M.S. McGlone, and R.P. Duncan. 2009. Are treelines advancing? A global meta-analysis of treeline response to climate warming. Ecology Letters 12:10401049.

Hoff, R.J. 1992. How to recognize blister rust infection on whitebark pine. USDA Forest Service, Intermountain Research Station, Ogden, UT. Research Note INT-406.

Hoff, R.J., D.E. Ferguson, G.I. McDonald, and R.E. Keane. 2001. Strategies for managing whitebark pine in the presence of white pine blister rust. In: D.F. Tomback, S.F. Arno, and R.E. Keane (eds.). Whitebark Pine Communities: Ecology and Restoration. Island Press, Washington, D.C, pp. 346-366.

Hutchins, H.E., and R.M. Lanner. 1982. The central role of Clark's Nutcracker in the dispersal and establishment of whitebark pine. Oecologia, 55:192-201.

Kearns, H.S.J., and W.R. Jacobi. 2007. The distribution and incidence of white pine blister rust in central and southeastern Wyoming and northern Colorado. Canadian Journal of Forest Research 37:462-472.

Klasner, F.L., and D.B. Fagre. 2002. A half century of hange in alpine treeline patterns at Glacier National Park, Montana, USA. Arctic, Antarctic, and Alpine Research 34:49-56.

Malanson, G.P., D.R. Butler, D.B. Fagre, S.J. Walsh, D.F. Tomback, L.D. Daniels, L.M. Resler, W.K. Smith, D.J. Weiss, D.L. Peterson, A.G. Bunn, C.A. Hiemstra, D. Liptzin, P.S. Bourgeron, Z. Shen, and C.I. Millar. 2007. Alpine treeline of western North America and global climate change: Linking organism-to-landscape dynamics. Physical Geography 28:378-396.

McCaughey, W.W., and D.F. Tomback. 2001. The natural regeneration process. In: D.F. Tomback, S.F. Arno, and R.E. Keane (eds.). Whitebark Pine Communities: Ecology and Restoration. Island Press, Washington, D.C, pp. 105-120.

McDonald, J.H. 2009. Handbook of Biological Statistics, 2nd ed. Sparky House Publishing. Baltimore, MD.

McKinney, S. T., and D. F. Tomback. 2007. The influence of white pine blister rust on seed dispersal in whitebark pine. Canadian Journal of Forest Research 37:1044-1057. 
Pyatt. 2013. The role of whitebark pine as a tree island initiator in the alpine-treeline ecotone: Examining microclimate and microsite. [Thesis]. The University of Colorado, Denver, Denver, CO.

Resler, L.M., D.R. Butler, and G.P. Malanson. 2005. Topographic shelter and conifer establishment and mortality in an alpine environment, Glacier National Park, Montana. Physical Geography 26: 112-125.

Resler, L.M., and D.F. Tomback. 2008. Blister rust prevalence in krummholz whitebark pine: Implications for treeline dynamics. Arctic, Antarctic and Alpine Research 40:161-170.

Resler, L.M., and M.A. Fonstad. 2009. A Markov analysis of tree islands at alpine treeline. In: D.R. Butler, G.P. Malanson, S.J. Walsh, and D.B. Fagre (eds.). The changing alpine treeline in Glacier National Park, Montana, USA. Elsevier, The Netherlands. pp. 151165.

Resler, L.M., Y. Shao, D.F. Tomback, and G.P. Malanson. 2014. Predicting functional role and occurrence of whitebark pine (Pinus albicaulis) at alpine treelines: Model accuracy and variable importance. Annals of the Association of American Geographers 104:703-722.

Romme, W.H., and M.G. Turner. 1991. Implications of global climate change for biogeographic patterns in the Greater Yellowstone Ecosystem. Conservation Biology 5:373386.

Schrag, A.M., A.G. Bunn, and L.J. Graumlich. 2008. Influence of bioclimatic variables on treeline conifer distribution in the Greater Yellowstone Ecosystem: Implications for species of concern. Journal of Biogeography 35:698-710.

Smith, E.K., L.M. Resler, E. Vance, L.W. Carstensen, and K.N. Kolivras. 2011. Modeling the incidence of white pine blister rust infection in whitebark pine at alpine treeline in the Northern Rocky Mountains using GIS. Arctic, Antarctic and Alpine Research 43:107-117.

Smith, W.K., M.J. Germino, T.E. Hancock, and D.M. Johnson. 2003. Another perspective on altitudinal limits of alpine timberlines. Tree Physiology 23:1101-1112.
Smith-McKenna, E.K., L.M. Resler, D.F. Tomback, H. Zhang, and G.P. Malanson. 2013. Topographic influences on the distribution of white pine blister rust in Pinus albicaulis treeline communities. ÉcoScience 20:215229.

Smith-McKenna, E.K., G.P. Malanson, L.M. Resler, L.W. Carstensen, S. P. Prisley, and D.F. Tomback. 2014. Feedbacks, disease, and climate influences on treeline pattern and process: An agent-based model application. Environmental Modelling and Software 62:85-96.

Tomback, D.F. 1982. Dispersal of whitebark pine seeds by Clark's Nutcracker: A mutualism hypothesis. Journal of Animal Ecology 51:451-467.

Tomback, D.F. 1986. Post-fire regeneration of krummholz whitebark pine: A consequence of nutcracker seed caching. Madroño 33:100110.

Tomback, D.F., and L.M. Resler. 2007. Invasive pathogens at alpine treeline: Complications and concerns. Physical Geography 28:397418.

Tomback, D.F., and P. Achuff. 2010. Blister rust and western forest biodiversity: Ecology, values and outlook for white pines. Forest Pathology 40:186-225.

Tomback, D.F., S.F. Arno, and R.E. Keane. 2001. The compelling case for management intervention. In: D.F. Tomback, S.F. Arno, and R.E. Keane (eds.). Whitebark Pine Communities: Ecology and Restoration. Island Press, Washington, D.C. pp. 3- 25.

Tomback, D.F., K.G. Chipman, L.M. Resler, E.K. Smith-McKenna, and C.M. Smith. 2014. Relative abundance and functional role of whitebark pine at treeline in the Northern Rocky Mountains. Arctic, Antarctic, and Alpine Research 46:407-418.

Young, K.R., and B. León. 2007. Tree-line changes along the Andes: Implications of spatial patterns and dynamics. Philosophical Transactions of the Royal Society B 362:263272. 